\title{
Dehydrocyclization of $\boldsymbol{n}$-octane over boron- and barium-doped $\mathrm{V}$-Mg-O catalysts: influence of $\boldsymbol{n}$-octane/oxygen ratios
}

\author{
Elwathig A. Elkhalifa ${ }^{1,2} \cdot$ Holger B. Friedrich ${ }^{2}$
}

Received: 16 November 2015/ Accepted: 6 December 2016/Published online: 26 December 2016

(C) The Author(s) 2016. This article is published with open access at Springerlink.com

\begin{abstract}
Boron- and barium-doped vanadium-magnesium oxide catalysts $(\mathrm{BVMgO}$ and $\mathrm{BaVMgO})$ were synthesized by the wet impregnation method and were used for the oxidative dehydrogenation of $n$-octane at different $n$ octane $/ \mathrm{O}_{2}$ molar ratios. The catalysts were characterized by ICP-OES, in situ XRD, ${ }^{51} \mathrm{~V}$ MAS NMR, SEM, EDX and TGA-DSC. The catalytic tests were carried out in a continuous flow fixed bed reactor. The incorporation of boron and barium as dopants into the $\mathrm{VMgO}$ system resulted in catalysts with some differences in properties, such as the details of phase transformations, porosity and degree of hydration. The catalytic performance was affected by the strength of the oxidative environment. Moreover, incorporation of barium enhanced the catalytic performance of $\mathrm{VMgO}$, while the addition of boron adversely affected the performance of $\mathrm{VMgO}$ over all $n$-octane $/ \mathrm{O}_{2}$ molar ratios with regard to both activity and oxidative dehydrogenation selectivity.
\end{abstract}

Keywords Dehydrocyclization - Boron dopant · Barium dopant $\cdot \mathrm{VMgO} \cdot n$-Octane

Elwathig A. Elkhalifa

wathigae@yahoo.com; elwathigae@uofk.edu

1 Department of Chemistry, Faculty of Science, University of Khartoum, Khartoum, Sudan

2 School of Chemistry and Physics, University of KwaZulu-Natal, Durban 4000, South Africa

\section{Introduction}

The gas-to-liquid processes (GTL) that are becoming more and more widely used for fuel production, produce longchain alkanes, including $n$-octane, as by-products. Due to the increasing demand for alkenes and aromatics in the polymer industry, there is a growing tendency in the petrochemical industry to the usage of these readily available alkanes to produce alkenes and aromatics. Although the non-oxidative dehydrogenation of alkanes has already been commercialized [1, 2], the oxidative dehydrogenation $(\mathrm{ODH})$ represents a potential alternative route for the production of olefins and aromatics, as no thermodynamic equilibrium limitations or coke formation are expected. Moreover, possibilities for cracking product formation may be minimized by employing ODH, as operating at relatively low temperatures would be possible. The great challenge in the ODH, however, is to stop the reaction at intermediate stages (formation of olefins and aromatics), and not allow it to proceed further to form the thermodynamically stable carbon oxides (undesirable combustion products) [3]; especially when a strong oxidant such as oxygen (air) is used. The catalyst's properties, as well as the operational conditions, are crucial in determining which of the above products will dominate.

Research on the catalytic activation of $n$-octane was dominated by the non-oxidative activation [4-13], and when oxygen was used for such activation (usually from air) the focus was on the production of hydrogen, syngas, as well as the short-chain olefins [14-20]. A common feature in these studies was that the linear octenes and styrene were either not formed or formed in small amounts. This is consistent with the fact that long-chain alkanes are prone towards cracking. In this context, the catalyst choice seems to be crucial in securing a successful pathway from 
$n$-octane to linear octenes and aromatics, especially in a reaction environment that contains oxygen. The ODH of alkanes in general is believed to proceed via a redox mechanism [21]. The participation of lattice oxygen in this mechanism was inferred from pulse experiments and isotopic studies [3, 22, 23]. Selectivity to the dehydrogenation product is deemed to be affected by the acid-base character of the catalyst, the mobility of the lattice oxygen, the atomic arrangements around the active sites, and the reducibility of the cation involved in the active centres $[21,24]$. It is clear from this, and from the mechanism of alkane activation, that in the oxidative activation of alkanes, the catalyst choice is very important in determining the selectivity to a certain class of products, e.g. dehydrogenation, oxygenates, or cracking products. The VMgO system was not known for the formation of either oxygenates or cracked products during the dehydrogenation of short-chain alkanes [21, 25-30]. Thus, VMgO catalysts were employed in our laboratories for the ODH of $n$-octane to produce octenes and C8 aromatics [31-33]. In these studies, reasonable selectivities for the dehydrogenation products were obtained.

The modification of properties of a given catalyst, and hence its catalytic performance, may be attempted by employment of dopants (promoters). The dopants can influence the acid-base character of the catalysts, the metal-oxygen bond, electronic structure around the active sites and the isolation of these sites $[34,35]$. The properties of the $\mathrm{VMgO}$ catalysts may be influenced by the addition of a suitable promoter, and hence its catalytic properties may also be modified. Different dopants have been studied with the $\mathrm{VMgO}$ catalysts, and different effects were observed [28, 36-42]. Boron- and barium-doped catalysts were employed in the ODH of $n$-octane at $n$-octane/oxygen molar ratio of 0.8 [43]. Boron and barium are different in their acid-base properties, electronegativity, as well as other properties like atomic size and charge/radius ratio. Therefore, it is likely that they will modify the $\mathrm{VMgO}$ system in different ways.

Besides the intrinsic properties of the $\mathrm{VMgO}$ system that favour the dehydrogenation route over oxygenates and cracking products formation, factors like the type of oxidant used as well as the alkane to oxygen ratio are also critical in determining the selectivity pattern to different products. The $\mathrm{MgO}$ support itself has been shown to make a minimal contribution to $n$-octane activation [44]. Since long-chain alkanes are prone to cracking, the dehydrogenation of such alkanes like $n$-octane to produce octenes and C8 aromatics must be conducted with extra caution. In our previous studies in n-octane activation, catalyst' activity and selectivities were found to be influenced by the $n$-octane to oxygen ratios $[32,45]$. Thus, the investigation of a factor like $n$-octane/oxygen ratios during the $n$-octane dehydrogenation over these doped $\mathrm{VMgO}$ catalysts would be informative.

\section{Experimental}

\section{Catalyst synthesis and characterization}

Magnesium oxide was prepared from magnesium oxalate by a procedure similar to that outlined in [31]. For the synthesis of the barium doped catalyst (BaVMgO), $700 \mathrm{ml}$ of a hot aqueous solution that contained $1.030 \mathrm{~g}$ of ammonium metavanadate was added to $4.6427 \mathrm{~g}$ of $\mathrm{MgO}$. The resultant solution was magnetically stirred and heated to $80{ }^{\circ} \mathrm{C}$. After $30 \mathrm{~min}, 200 \mathrm{ml}$ of a hot aqueous solution that contained $0.0626 \mathrm{~g}$ of barium carbonate was added to the hot solution that contained magnesium and vanadium. Heating and magnetic stirring was continued till a paste was formed. The paste was placed overnight in an oven at $110{ }^{\circ} \mathrm{C}$. The catalyst so-obtained was ground, thoroughly mixed and was then calcined at $550{ }^{\circ} \mathrm{C}$ for $5 \mathrm{~h}$ (the temperature ramping during the calcination was $\left.1.5^{\circ} / \mathrm{min}\right)$. The calcined catalyst was pelletized, crushed, and sieved to a 600-1000 $\mu \mathrm{m}$ mesh size. The same procedure was performed for the synthesis of the boron-doped catalyst (BVMgO); boric acid was used as a source for boron. The synthesis of the undoped catalyst (VMgO) is discussed elsewhere [31].

In situ XRD was performed in a flow of air $(20 \mathrm{ml} / \mathrm{min})$ using a Bruker AXS diffractometer equipped with a TCU 750 temperature control unit and operating at $40 \mathrm{kV}$ and $40 \mathrm{~mA}$. The source of radiation was $\mathrm{Cu} \mathrm{K \alpha}$. The ${ }^{51} \mathrm{~V}$ magic angle spinning nuclear magnetic resonance (MAS NMR) spectra were recorded at $600 \mathrm{MHz}$ on a Bruker Avance III 600 NMR Spectrometer fitted with a Bruker Solid State Probe. The catalyst sample was packed in a cylindrical zirconia rotor that was rotated at a speed of $12 \mathrm{kHz}$ during the data acquisition. SEM images were obtained using a LEO 1450 Scanning Electron Microscope. EDX was carried out using a Jeol JSM 6100 Scanning Electron Microscope equipped with a Bruker EDX detector. Samples for SEM images were coated with gold using a Polaron SC Sputter Coater, while those for the EDX were coated with carbon in a Jeol JEE-4C Vacuum Evaporator. Thermal analysis (TGA and DSC) was performed on an SDT Q600 TGA-DSC instrument in static air atmosphere. The sample (ca. $5 \mathrm{mg}$ ) was contained in an alumina crucible. The temperature was raised from ambient to $1000{ }^{\circ} \mathrm{C}$ at a heating rate of $10 \% \mathrm{~min}$.

\section{Catalytic testing}

The catalytic testing was carried out in a fixed bed continuous flow reactor that operated in a down flow mode. 
The reactor tube was stainless steel; the tube was $220 \mathrm{~mm}$ in length and $10 \mathrm{~mm}$ in internal diameter. Air was used as an oxidant and nitrogen as a make-up gas. The flow rates of nitrogen and gaseous $n$-octane were varied to give the required total flow $(134 \mathrm{ml} / \mathrm{min})$ and the $n$-octane $/ \mathrm{O}_{2}$ molar ratios $(0.1,0.4,0.8,1.2$ and 1.6). Before conducting any catalytic experiment, the air and nitrogen flow rates were set to the desired values using air and nitrogen rotameters, respectively, and the flow of each gas was further rechecked using a Perkin Elmer PE 1000 electronic flowmeter. An HPLC pump was used to deliver the $n$-octane to the reactor. The volume of the gas phase during the catalytic run was determined by a Ritter DrumType Gas Metre. The products of the catalytic testing were analyzed off-line using a Perkin-Elmer Clarus500 Gas Chromatograph equipped with both an FID and a TCD; the FID for the organic products and the TCD for the carbon oxides. For the capillary column attached to the FID (PONA), the carrier gas was hydrogen that flowed at $2.0 \mathrm{ml} / \mathrm{min}$. For the capillary column attached to the TCD (Carboxen 1006 PLOT), the carrier gas was helium that flowed at $6.0 \mathrm{ml} / \mathrm{min}$. An $870 \mathrm{KF}$ Titrino plus (Metrohm) Karl Fischer Titrator was used to determine the weight percentage of water in both the organic and aqueous layers that formed by the catalytic tests. The catalyst volume was $1 \mathrm{ml}$ (ca. $0.45 \mathrm{~g}$ ) and the catalyst pellets sizes were between 600 and $1000 \mu \mathrm{m}$. The catalytic tests were carried out at $450{ }^{\circ} \mathrm{C}$ and at a gas hourly space velocity (GHSV) of $8000 \mathrm{~h}^{-1}$. The $\mathrm{VMgO}$ catalysts (doped and undoped) were tested at different $n$-octane to oxygen molar ratios, as it has been shown in our previous studies of $n$-octane activation that this parameter ( $n$-octane/oxygen ratio) has a great influence on the catalytic activity and selectivity $[32,45]$. The flow rates of gaseous $n$-octane/air/nitrogen in these experiments were $1.5 / 72 /$ $61,6 / 72 / 56,12 / 72 / 50,18 / 72 / 44$ and 24/72/38, which correspond to $n$-octane $/ \mathrm{O}_{2}$ molar ratios of $0.1,0.4,0.8,1.2$ and 1.6, respectively. Conversion and selectivity were calculated on a carbon basis (carbon balances were in the range of 97-101\%), and all experiments were carried out in duplicate.

\section{Results and discussion}

\section{Characterization}

The synthesized catalysts were characterized by ICP-OES, in situ XRD, MAS NMR spectroscopy, SEM, EDX and TGA-DSC. As determined by the ICP-OES, the concentrations of boron and barium (by weight) in the doped $\mathrm{VMgO}$ catalysts were 1.3 and $1.2 \%$, respectively.

\section{In situ XRD}

In situ XRD was carried out on the uncalcined catalysts in a bid to investigate phase transformations. These XRD experiments were conducted under a flow of air, i.e. under conditions similar to those under which the calcination of the catalysts was performed. The importance of phase transformations is that they are believed to affect the chemical and textural properties of the resultant catalyst after calcination $[46,47]$. The in situ XRD diffractograms of $\mathrm{BVMgO}$ and $\mathrm{BaVMgO}$ catalysts are given in Fig. 1a, b, respectively. The lines assignments of these diffractograms were made according to $[25,46,48]$. At $50{ }^{\circ} \mathrm{C}$, the XRD diffractograms of the doped catalysts ( $\mathrm{BVMgO}$ and $\mathrm{BaVMgO}$ ) showed lines characteristic of $\mathrm{Mg}(\mathrm{OH})_{2}$ at $2 \theta$ equal to $18.5^{\circ}, 38^{\circ}, 50.5^{\circ}$ and $59^{\circ}$ ( $d$ spacings of $4.78,2.37,1.8$ and $1.57 \AA$, respectively). At 100 and $150^{\circ} \mathrm{C}$, the diffractograms of these doped catalysts were still characterized by the existence of $\mathrm{Mg}(\mathrm{OH})_{2}$ as a main crystalline phase. However, at these temperatures, the diffractograms of each of the doped catalysts also showed a weak line that is assignable to the magnesium orthovanadate; at $2 \theta$ equal to $35.5^{\circ}$ ( $d$ spacing of 2.52 $\AA$ ) for $\mathrm{BVMgO}$ and at $2 \theta$ equal to $23^{\circ}(d$ spacing of $3.7 \AA$ ) for
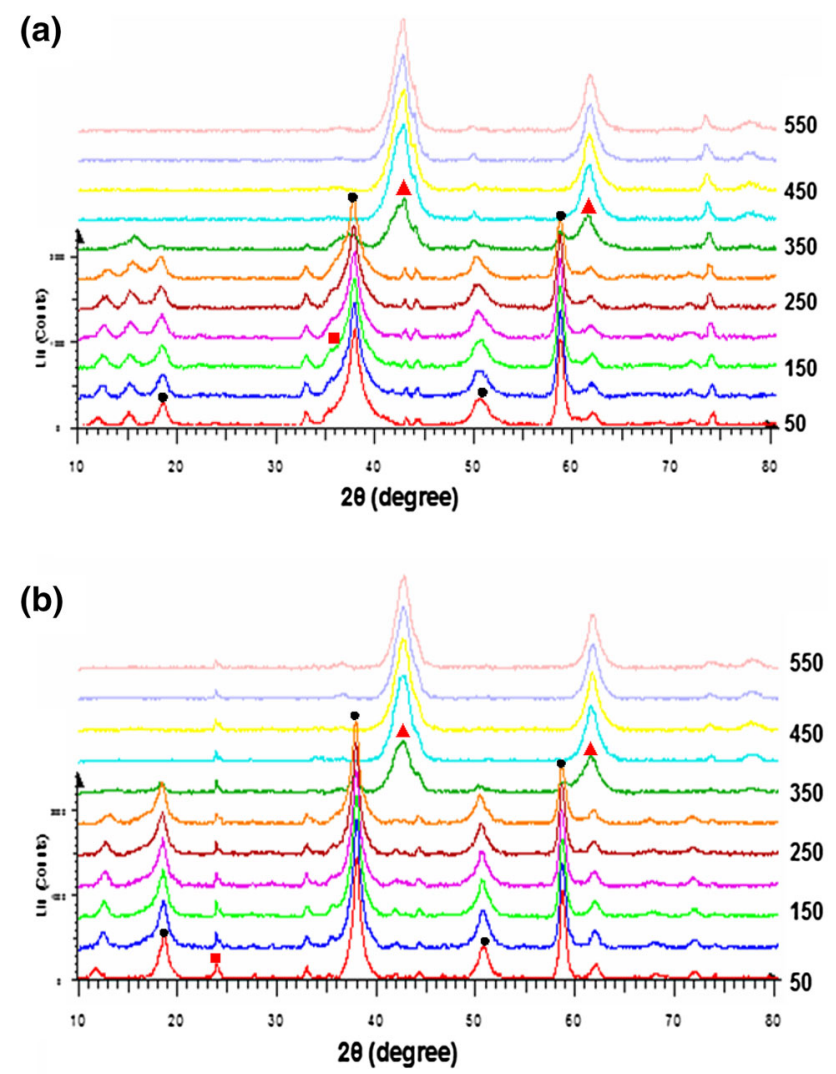

Fig. 1 a In situ XRD of the $\mathrm{BVMgO}$ catalyst [filled circle for $\mathrm{Mg}(\mathrm{OH})_{2}$, filled triangle for $\mathrm{MgO}$, and filled square for $\left.\mathrm{Mg}_{3}\left(\mathrm{VO}_{4}\right)_{2}\right]$. b In situ XRD of the BaVMgO catalyst [filled circle for $\mathrm{Mg}(\mathrm{OH})_{2}$, filled triangle for $\mathrm{MgO}$, and filled square for $\left.\mathrm{Mg}_{3}\left(\mathrm{VO}_{4}\right)_{2}\right]$

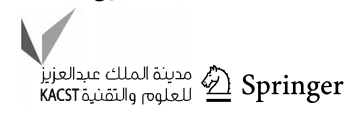


$\mathrm{BaVMgO}$ (Fig. 1a, b, respectively). A noticeable difference between $\mathrm{BVMgO}$ and $\mathrm{BaVMgO}$ is that the diffractogram of the $\mathrm{BVMgO}$ catalyst at $200{ }^{\circ} \mathrm{C}$ (Fig. 1a) showed a line attributable to $\mathrm{MgO}$ at $2 \theta$ equal to $43^{\circ}$ ( $d$ spacing of $2.1 \AA$ ); however, $\mathrm{Mg}(\mathrm{OH})_{2}$ is still the dominant crystalline phase of both catalysts. This phase composition continues up to $300{ }^{\circ} \mathrm{C}$. At $350{ }^{\circ} \mathrm{C}$, the existence of $\mathrm{MgO}$ as the main crystalline phase can be inferred from the lines at $2 \theta$ equal to $43^{\circ}$ and $62^{\circ}$ ( $d$ spacings of 2.11 and $1.5 \AA$, respectively); the line assignable to $\mathrm{Mg}(\mathrm{OH})_{2}(d$ spacing of $2.37 \AA$ ) was still present for both doped catalysts. Worth mentioning here is that Oganowski et al. [49] attributed this line to the existence of a hydrated form of magnesium vanadate $\left[\mathrm{Mg}_{3}(\mathrm{OH})_{2}-\right.$ $\mathrm{V}_{2} \mathrm{O}_{7}\left(\mathrm{H}_{2} \mathrm{O}\right)_{2}$ ]. A noticeable difference between the doped catalyst on one hand and the undoped catalysts on the other hand was that $\mathrm{MgO}$ was detected in the undoped catalyst $(\mathrm{VMgO})$ for the first time at $350{ }^{\circ} \mathrm{C}$ and became the dominant crystalline phase at $400{ }^{\circ} \mathrm{C}$ and above [32]; i.e. both dopants caused the crystalline $\mathrm{MgO}$ to form from $\mathrm{Mg}(\mathrm{OH})_{2}$ at lower temperatures. For the doped catalysts $(\mathrm{BVMgO}$ and $\mathrm{BaVMgO}$ ), the only crystalline phases detected at 400,450 , 500 and $550{ }^{\circ} \mathrm{C}$ were $\mathrm{MgO}$ by the lines at $2 \theta$ equal to 43 and $62^{\circ}$ ( $d$ spacings of 2.11 and $1.50 \AA$, respectively) and magnesium orthovanadate by the line at $2 \theta$ equal to $44^{\circ}$ ( $d$ spacing of $2.05 \AA$ ). Worth noting is that the existence of the orthovanadate in the undoped catalyst at these temperatures, viz. $400,450,500$ and $550{ }^{\circ} \mathrm{C}$, was indicated by the lines at the $d$ spacings of 3.04 and $2.5 \AA$ [32]. This indicates that magnesium orthovanadate in the doped catalysts $(\mathrm{BVMgO}$ and $\mathrm{BaVMgO}$ ) exhibited different crystal planes than those shown by the undoped catalysts $(\mathrm{VMgO})$.

\section{${ }^{51} \mathrm{~V}$ magic angle spinning nuclear magnetic resonance (MAS NMR)}

In our previous study [43], the MAS NMR spectroscopy on the calcined catalysts (doped and undoped), indicated that vanadium exists as tetrahedrally coordinated $\mathrm{V}^{5+}$ species in coordination environments similar to that of orthovanadate. To get more insights, the MAS NMR spectroscopy was performed on the uncalcined catalysts. The ${ }^{51}$ V MAS NMR spectroscopy of the undoped catalyst (Fig. 2a) shows a band at $-660 \mathrm{ppm}$. This, according to [50, 51], suggests that vanadium in the undoped catalyst $(\mathrm{VMgO})$ exists as dimeric $\mathrm{VO}_{4}$ tetrahedra in a coordination environment similar to that of $\mathrm{V}_{2} \mathrm{O}_{7}{ }^{4-}$, i.e. with the corner-sharing of two $\mathrm{VO}_{4}$ tetrahedra through a bridging oxygen atom. In a different observation, the spectra of the doped catalysts (BVMgO and $\mathrm{BaVMgO})$ showed a band at -545 ppm (Fig. 2b, c, respectively). According to the assignments in [50,51], this indicates that vanadium in the doped catalysts exists as isolated $\mathrm{VO}_{4}$ tetrahedra in a coordination environment similar to that of $\mathrm{VO}_{4}{ }^{3-}$. This suggests that the incorporation of boron and

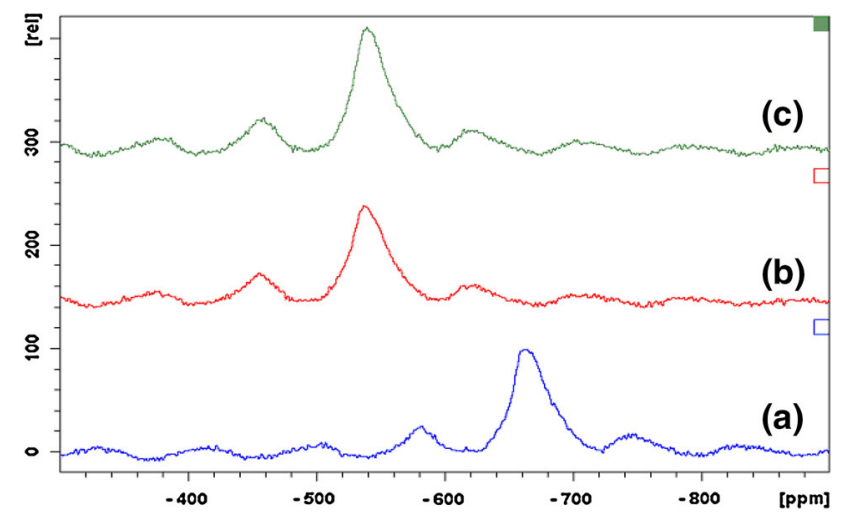

Fig. $2{ }^{51} \mathrm{~V}$ MAS NMR spectra of the uncalcined catalysts:( $\left.a\right)$ $\mathrm{VMgO},(b) \mathrm{BVMgO}$, and (c) $\mathrm{BaVMgO}$

barium into the $\mathrm{VMgO}$ system hinders the corner sharing of the $\mathrm{VO}_{4}$ tetrahedra. This is consistent with the observation from the in situ XRD results that the dopants cause the $\mathrm{MgO}$ to form from $\mathrm{Mg}(\mathrm{OH})_{2}$ at lower temperatures compared to that of the undoped catalyst; it was reported that the formation of the orthovanadate phase is somewhat associated with the transformation of $\mathrm{Mg}(\mathrm{OH})_{2}$ into $\mathrm{MgO}$ during the calcination of the $\mathrm{VMgO}$ catalyst [49].

\section{Scanning electron microscopy (SEM)}

As Fig. 3 shows, the SEM micrographs of the three catalysts display fluffy, rough surfaces with a platelet-like structure. The surfaces of $\mathrm{VMgO}$ and $\mathrm{BVMgO}$ (Fig. 3a, b) show more cavities than that of $\mathrm{BaVMgO}$ (Fig. 3c), which indicates that these two catalysts are more porous than $\mathrm{BaVMgO}$; this is in an agreement with the values obtained from the pore volume analysis [43], viz. $0.75,0.75$ and $0.64 \mathrm{~cm}^{3} / \mathrm{g}$ for $\mathrm{VMgO}$, $\mathrm{BVMgO}$ and $\mathrm{BaVMgO}$, respectively.

\section{Thermogravimetric analysis (TGA) and differential scanning calorimetry (DSC)}

As suggested by the TGA and DSC results (Table 1), the three catalysts generally exhibit similar thermal behaviour. In each of the three catalysts, the thermal analysis shows an endothermic effect at around $130{ }^{\circ} \mathrm{C}$, which is likely to be due to the removal of weakly bonded water molecules. Considering the weight loss for this effect (Table 1), the higher value in the case of $\mathrm{BVMgO}$ indicates that this catalyst is more hydrated than the other two. This is consistent with the acidic character of boron which is likely to enhance interaction with the lone pairs of electrons in the water molecules. Another weight loss was recorded at $350-390{ }^{\circ} \mathrm{C}$. Considering the assignments in $[49,52]$, this weight loss may be attributed to the removal of strongly bonded water molecules. Interestingly, this weight loss was 

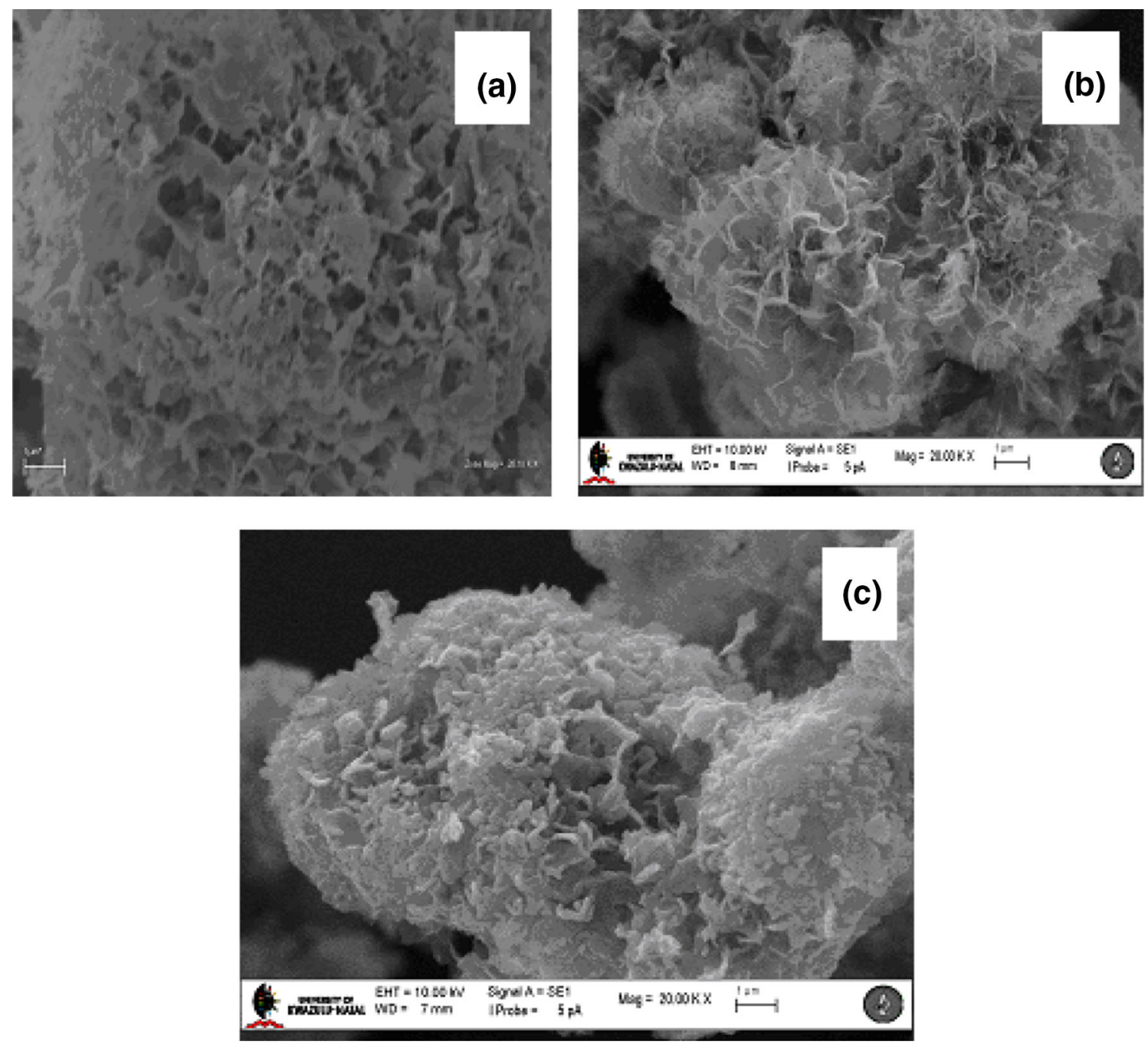

Fig. 3 SEM micrographs (20,000 times magnification) of a $\mathrm{VMgO}, \mathbf{b} \mathrm{BVMgO}$, and $\mathbf{c} \mathrm{BaVMgO}$

Table 1 Thermal analysis data

\begin{tabular}{lllll}
\hline Catalyst & Effect (1) (temperature $\left.{ }^{\circ} \mathrm{C}\right)$ & Effect $(1)($ weight loss $\%)$ & Effect (2) (temperature $\left.{ }^{\circ} \mathrm{C}\right)$ & Effect $(2)($ weight loss $\%)$ \\
\hline $\mathrm{VMgO}$ & 130 & 8.0 & 350 & 8.3 \\
$\mathrm{BVMgO}$ & 140 & 12.2 & 390 & 9.2 \\
$\mathrm{BaVMgO}$ & 130 & 8.6 & 360 & 9.7 \\
\hline
\end{tabular}

not accompanied by observable heat change. This suggests that the removal of these strongly bonded water molecules was accompanied by a form of crystallization, and that the endothermic effect induced by the removal of water was equated by the exothermic effect of the postulated crystallization.

\section{Catalytic activity}

It is clear from Fig. 4 that the catalytic activity is sensitive to the change in the $n$-octane to oxygen molar ratios.
Enriching the reactant mixture with oxygen causes a significant increase in the conversion of $n$-octane. The oxygen-rich reactant mixture represents a strong oxidative environment that enhances the formation of the thermodynamically stable carbon oxides, which results in pushing the equilibrium far to the right, and consequently leads to high conversion. As Fig. 4 displays, the boron-doped catalyst shows the lowest conversion at all the ratios. The lower conversion over $\mathrm{BVMgO}$ is in agreement with the TPR data [43], as this catalyst shows the highest values for both Tmax and onset temperature when compared to 


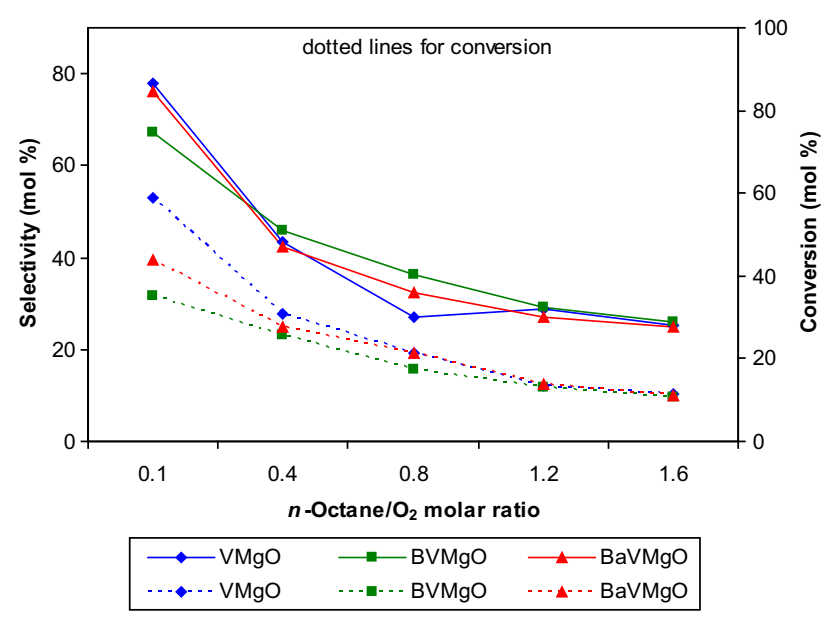

Fig. $4 n$-Octane conversion and selectivity to carbon oxides at different $n$-octane $/ \mathrm{O}_{2}$ ratios

$\mathrm{BaVMgO}$ and $\mathrm{VMgO}$. This lower conversion over the $\mathrm{BVMgO}$ catalyst may be attributed to the decrease in the mobility of the lattice oxygen that is plausibly induced by the acidic and highly electronegative boron metal [43]. As Fig. 4 shows, the difference in conversion between the undoped $(\mathrm{VMgO})$ and the barium-doped $(\mathrm{BaVMgO})$ catalysts is widened at the $n$-octane to oxygen ratios of 0.4 and 0.1 (which corresponds to 4.5 and $1.1 \%$ (v/v) of gaseous $n$ octane in the reactant mixture); in these $n$-octane-lean environments, competitive adsorption between the components of the reactant mixture is likely to contribute much to the conversion.

\section{Selectivity to 1-octene and styrene}

Generally, high demand exists for linear alpha alkenes. 1Octene and styrene are valuable products that are used in the petrochemicals and polymers industry; in fact,

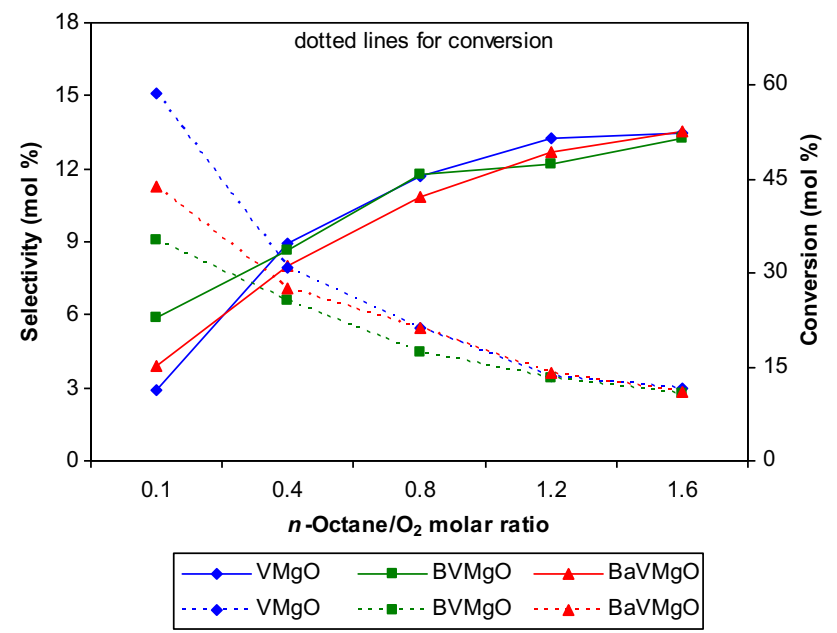

Fig. 5 Selectivity to 1 -octene at different $n$-octane $/ \mathrm{O}_{2}$ ratios polystyrene is one of the most important polymers. As Fig. 5 displays, selectivity to 1-octene goes parallel to the enrichment of the reactant mixture with $n$-octane (mild oxidative environments), which in turn is accompanied by low conversions. This is consistent with the following conceivable sequential reaction [33]:

$$
\begin{aligned}
n \text {-octane } & \rightarrow \text { octenes } \rightarrow \text { octadienes/octatrienes } \\
& \rightarrow \text { C } 8 \text { aromatics (styrene). }
\end{aligned}
$$

In this consecutive reaction, a strong oxidative environment will shift the reaction far to the right, and thereby lowers the selectivity to 1-octene; the opposite is true for the weak oxidative environment ( $n$-octane-rich mixture). In the above reaction, the stable aromatic nucleus in styrene, and in $\mathrm{C} 8$ aromatics in general, represents a driving force that pushes the reaction far to the right; in support of this was that only small amounts of octadienes and octatrienes were formed.

Opposite to the trend shown by 1-octene, enriching the reactant mixture with $n$-octane causes a noticeable decrease in the selectivity to styrene (Fig. 6). Consistent with the consecutive reaction postulated, enriching the reactant mixture with oxygen (strong oxidative environment), which is accompanied by an increase in the conversion, causes a noticeable increase in styrene selectivity, presumably by pushing the reaction far to the right. The exception to this, however, was at the $n$-octane/oxygen ratio of 0.1 , as a noticeable decrease in the styrene selectivity was observed. This decrease in the styrene selectivity at the ratio of 0.1 may be attributed to the extremely oxygen-rich environment where the formed styrene may be degraded, via secondary combustion, to form the thermodynamically stable carbon oxides. In support of this was that a steep increase in selectivity to $\mathrm{CO} x$ was observed when moving from the ratio 0.4 to 0.1 (Fig. 4). The $\mathrm{BaVMgO}$ catalyst exhibited the highest selectivity to

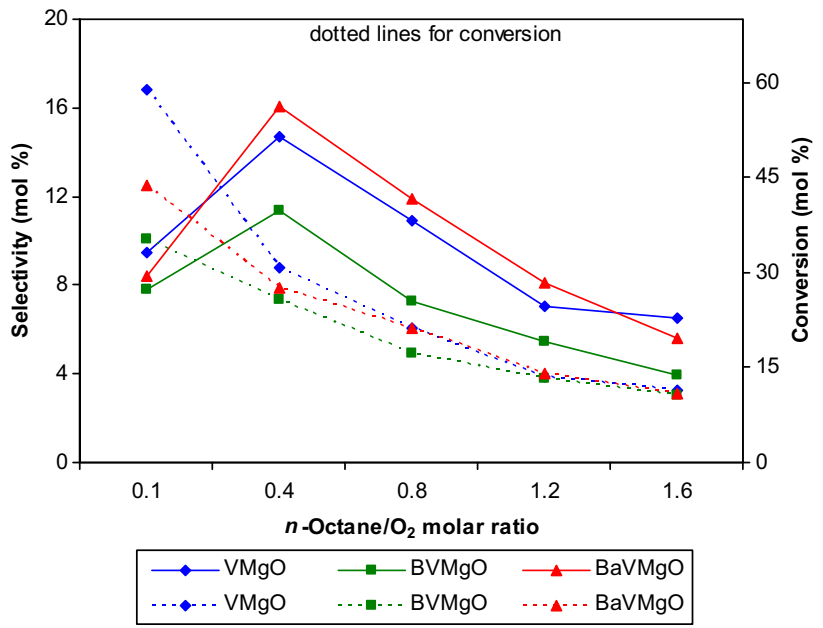

Fig. 6 Selectivity to styrene at different $n$-octane/ $\mathrm{O}_{2}$ ratios 
styrene at the ratios $0.4,0.8$, and 1.2 , while $\mathrm{BVMgO}$ catalyst showed the lowest selectivity to styrene at all the ratios. Worth mentioning is that the above-discussed observations, that related to the 1-octene and styrene selectivity, are applicable to the selectivity to octenes and $\mathrm{C} 8$ aromatics in general. To support these observations and to provide more data related to the main products of the catalytic testing, selectivity for octenes, C8 aromatics (ethylbenzene, styrene and $o$-xylene) and $\mathrm{CO} x$ are given in Table 2.

\section{Dehydrocyclization ability}

For the catalytic tests over the doped and the undoped catalysts, octenes and $\mathrm{C} 8$ aromatics represent the major $\mathrm{ODH}$ products. As indicated by the postulated reaction scheme, as well as by our previous studies [31,33], octenes are precursors to $\mathrm{C} 8$ aromatics and that further dehydrogenation and cyclization of the formed octenes will eventually lead to the formation of $\mathrm{C} 8$ aromatics. Therefore, the dehydrocyclization ability of these catalysts may be indicated by comparing the amounts of the formed octenes to the combined amounts of octenes and C8 aromatics (Fig. 7). As can be inferred from Fig. 7, the cyclization power increases (more aromatics and less octenes) as the $n$-octane $/ \mathrm{O}_{2}$ ratio decreases, i.e. as the reactant mixture is enriched with oxygen. Also, over all the $n$-octane $/ \mathrm{O}_{2}$ ratios, the dehydrocyclization power of $\mathrm{BaVMgO}$ is greater than that of $\mathrm{BVMgO}$, which indicates the better oxidative dehydrogenation performance of the former. In this respect, the barium-doped catalyst also exceeds the undoped one at the ratios of $0.4,0.8$ and 1.2. The variation in the dehydrocyclization power at different $n$-octane to oxygen ratios can also be seen when inspecting the selectivity of

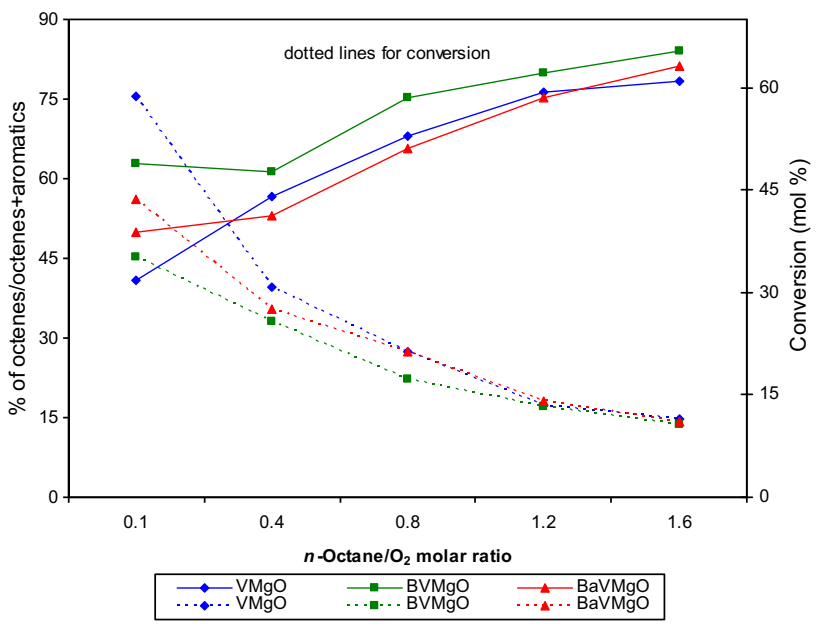

Fig. 7 Dehydrocyclization trends over the three catalysts at different $n$-octane $/ \mathrm{O}_{2}$ ratios

ethylbenzene and styrene. As shown in Fig. 8, the ethylbenzene selectivity gets closer to the styrene selectivity at the relatively higher $n$-octane $/ \mathrm{O}_{2}$ ratios (1.2 and 1.6); while in the oxygen-rich environments (ratios of 0.1 and 0.4 ), the selectivity to styrene is obviously greater than that to ethylbenzene. As styrene results from deeper dehydrogenation of $n$-octane when compared to ethylbenzene, this again suggested that the dehydrogenation performance is enhanced by enriching the reactant mixture with oxygen.

As elucidated above, the catalytic results of the ODH of $n$-octane over the two doped catalysts (BVMgO and $\mathrm{BaVMgO})$ at different $n$-octane $/ \mathrm{O}_{2}$ ratios indicated that the performance of the barium-doped catalyst was better than that over the boron-doped catalyst in both activity and selectivity to $\mathrm{ODH}$ products (octenes and $\mathrm{C} 8$ aromatics).

Table 2 Conversion and selectivity (mol\%) for the main products at different $n$-octane/ $\mathrm{O}_{2}$ molar ratios

\begin{tabular}{|c|c|c|c|c|c|c|}
\hline & \multirow[t]{2}{*}{ Catalyst } & \multicolumn{5}{|c|}{$\mathrm{C}_{8} \mathrm{H}_{18} / \mathrm{O}_{2}$ ratio } \\
\hline & & 0.1 & 0.4 & 0.8 & 1.2 & 1.6 \\
\hline \multirow[t]{3}{*}{ Conversion } & $\mathrm{VMgO}$ & 58.8 & 30.8 & 21.3 & 13.4 & 11.5 \\
\hline & $\mathrm{BVMgO}$ & 35.3 & 25.7 & 17.3 & 13.2 & 10.7 \\
\hline & $\mathrm{BaVMgO}$ & 43.7 & 27.6 & 21.3 & 14.0 & 11.0 \\
\hline \multirow[t]{3}{*}{ Octenes } & $\mathrm{VMgO}$ & 6.9 & 26.8 & 42.2 & 45.8 & 49.4 \\
\hline & BVMgO & 16.9 & 27.3 & 39.9 & 45.9 & 50.6 \\
\hline & $\mathrm{BaVMgO}$ & 9.7 & 24.6 & 36.2 & 45.9 & 50.0 \\
\hline \multirow[t]{3}{*}{ C8 Aromatics } & $\mathrm{VMgO}$ & 9.9 & 20.5 & 19.7 & 14.3 & 13.7 \\
\hline & $\mathrm{BVMgO}$ & 10.0 & 17.2 & 13.1 & 11.6 & 9.6 \\
\hline & $\mathrm{BaVMgO}$ & 9.8 & 21.8 & 19.0 & 15.2 & 11.7 \\
\hline \multirow[t]{3}{*}{$\mathrm{COx}$} & $\mathrm{VMgO}$ & 78.0 & 43.4 & 27.2 & 28.8 & 25.3 \\
\hline & $\mathrm{BVMgO}$ & 67.1 & 45.9 & 36.2 & 29.2 & 26.1 \\
\hline & $\mathrm{BaVMgO}$ & 76.0 & 42.3 & 32.3 & 26.9 & 24.8 \\
\hline
\end{tabular}




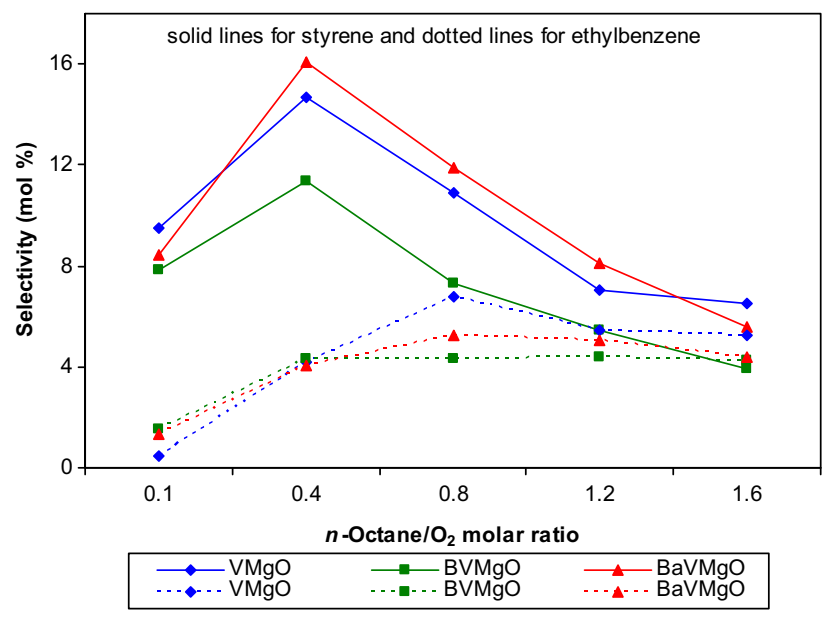

Fig. 8 Selectivity of ethylbenzene and styrene

Table 3 Properties of the used catalysts

\begin{tabular}{lll}
\hline Catalyst & Crystallite size from XRD $(\mathrm{nm})$ & $\mathrm{V}_{2} \mathrm{O}_{5} \mathrm{wt} \%(\mathrm{EDX})$ \\
\hline $\mathrm{VMgO}$ & $16.6(7.0)^{\mathrm{a}}$ & $20.5(19.7)$ \\
$\mathrm{BVMgO}$ & $10.6(5.5)$ & $16.3(19.4)$ \\
$\mathrm{BaVMgO}$ & $17.7(5.6)$ & $18.1(17.3)$ \\
\hline
\end{tabular}

a The values in parentheses are for the fresh catalysts

\section{Characterization of the used catalysts}

To investigate any possible chemical or textural changes, characterization was carried out on the used catalysts; namely, powder XRD, EDX and ICP-OES. Worth mentioning is that the time-on-stream during the catalytic testing was $120 \mathrm{~h}$. In a similar observation to those reported in $[32,53]$ for the used $\mathrm{VMgO}, \mathrm{XRD}$ on the used $\mathrm{BVMgO}$ and $\mathrm{BaVMgO}$ catalysts indicates no change in the crystalline phases, as only magnesium oxide and magnesium orthovanadate were detected. Regarding the textural properties (Table 3), the catalytic testing induced an increase in the average crystallite sizes, as calculated from the XRD using the Scherrer equation. In the same trend as that observed for the undoped catalysts [32], the increase in the crystallite size goes parallel to the catalytic activity, which again suggests that this change is probably due to the redox cycle and the accompanying order/disorder reconstruction. Based on the EDX results (Table 3), it may be said that there was no observable change in vanadium concentration at the surface of $\mathrm{BaVMgO}$ catalyst, as well as for $\mathrm{VMgO}$. For the $\mathrm{BVMgO}$ catalyst, however, a slight change (a decrease) in the vanadium surface concentration may have been induced by the catalytic testing; however, worth mentioning here is that the ICP-OES test on the used catalysts did not show elemental change.

\section{Conclusions}

Investigation of the phase transformations during the catalysts calcination indicated that in the boron-doped catalyst the $\mathrm{MgO}$ started to form at lower temperature, namely $200{ }^{\circ} \mathrm{C}$. Also, for both doped catalysts, $\mathrm{MgO}$ was the dominant crystalline phase at $350{ }^{\circ} \mathrm{C}$; for the undoped catalyst, $\mathrm{MgO}$ became the main crystalline phase at $400{ }^{\circ} \mathrm{C}$ and above. The magnesium orthovanadate phase existed in the doped catalysts; however, it exhibited crystal planes different from those shown by the undoped catalyst. Some differences between the $\mathrm{BaVMgO}$ and $\mathrm{BVMgO}$ were also observed, e.g. the former is less porous, while the latter is more hydrated. Moreover, no changes in the crystalline phases were detected in the used catalysts; however, some changes that related to the textural properties were observed. The catalytic testing showed that the doped catalysts maintained the main features (merits) of the undoped $\mathrm{VMgO}$ catalysts with regard to the low propensity to form oxygenates and cracking products under all $n$-octane $/ \mathrm{O}_{2}$ molar ratios. At all ratios, the $\mathrm{BVMgO}$ showed the lowest activity and ODH selectivity. Enriching the reactant mixture with oxygen (strong oxidative environment) increased the conversion, but at the same time enhanced the formation of the combustion products (carbon oxides). In this context, selectivity to 1 -octene increased as the ratio of $n$-octane to oxygen increased; the opposite was true for styrene (except for the $n$-octane to oxygen ratio of 0.1 ). The highest selectivity to styrene was observed over the $\mathrm{BaVMgO}$ catalyst at $n$-octane $/ \mathrm{O}_{2}$ molar ratios of $0.4,0.8$ and 1.2. In fact, the dehydrocyclization ability in general was greater over this catalyst $(\mathrm{BaVMgO})$ at these ratios. Generally, the bariumdoped catalyst $(\mathrm{BaVMgO})$ showed a better performance than the boron-doped catalyst (BVMgO) with regard to both the catalytic activity and the ODH selectivity.

Acknowledgements The authors acknowledge the financial support from the National Research Foundation (NRF) and the Technology and Human Resources for Industry Programme (THRIP), (South Africa). Thanks also go to the University of KwaZulu-Natal (South Africa) and University of Khartoum (Sudan).

Open Access This article is distributed under the terms of the Creative Commons Attribution 4.0 International License (http:// creativecommons.org/licenses/by/4.0/), which permits unrestricted use, distribution, and reproduction in any medium, provided you give appropriate credit to the original author(s) and the source, provide a link to the Creative Commons license, and indicate if changes were made.

\section{References}

1. Hornaday GF, Ferrell FM, Mills GA (1961) Manufacture of mono- and diolefins from paraffins by catalytic dehydrogenation. 
In: McKetta JJ Jr (ed) Advances in petroleum chemistry and refining, vol 4. Interscience, Pans

2. Bhasin MM, McCain JH, Vora BV, Imai T, Pujado PR (2001) Dehydrogenation and oxydehydrogenation of paraffins to olefins. Appl Catal A Gen 221:397-419

3. Hodnett BK (2000) Heterogeneous catalysis oxidation: fundamental and technological aspects of the selective and total oxidation of organic compounds. Wiley, New York, pp 66-101

4. Denayer JF, Baron GV, Vanbutsele G, Jacobs PA, Martens JA (2000) Evidence for alkylcarbenium ion reaction intermediates from intrinsic reaction kinetics of $\mathrm{C}_{6}-\mathrm{C}_{9} n$-alkane hydroisomerization and hydrocracking on $\mathrm{Pt} / \mathrm{H}-\mathrm{Y}$ and $\mathrm{Pt} / \mathrm{USY}$ zeolites. J Catal 190:469-473

5. Akhmedov VM, Al-Khowaiter SH, Al-Refai JK (2003) Hydroconversion of $\mathrm{C}_{5}-\mathrm{C}_{8}$ alkanes over $\mathrm{Zr}$-containing supported catalysts prepared by metal vapour method. Appl Catal A Gen 252:353-361

6. Jongpatiwut S, Sackamduang P, Rirksomboon T, Osuwan S, Resasco DE (2003) $n$-Octane aromatization on a Pt/KL catalyst prepared by vapour-phase impregnation. J Catal 218:1-11

7. Kuznetsov PN (2003) Study of $n$-octane hydrocracking and hydroisomerization over $\mathrm{Pt} / \mathrm{HY}$ zeolites using the reactors of different configurations. J Catal 218:12-23

8. Grau JM, Yori JC, Vera CR, Lovey FC, Condo AM, Parera JM (2004) Crystal phase dependent metal-supported interactions in $\mathrm{Pt} / \mathrm{SO} 42-\mathrm{ZrO} 2$ catalysts for hydroconversion of $n$-alkanes. Appl Catal A Gen 265:141-152

9. de Lucas A, Valverde JL, Sanchez P, Dorado F, Ramos MJ (2005) Hydroisomerization of $n$-octane over platinum catalysts with or without binder. Appl Catal A Gen 282:15-24

10. de Lucas A, Ramos MJ, Dorado F, Sanchez P, Valverde JL (2005) Influence of the $\mathrm{Si} / \mathrm{Al}$ ratio in the hydroisomerization of $n$ octane over platinum and palladium beta zeolite-based catalysts with or without binder. Appl Catal A Gen 289:205-213

11. de Lucas A, Sanchez P, Dorado F, Ramos MJ, Valverde JL (2005) Effect of the metal loading in the hydroisomerization of $n$ octane over beta agglomerated zeolite based catalysts. Appl Catal A Gen 294:215-225

12. Altwasser S, Welker C, Traa Y, Weitkamp J (2005) Catalytic cracking of $n$-octane on small-pore zeolites. Microporous Mesoporous Mater 83:345-356

13. Szechenyi A, Solymosi F (2006) n-Octane aromatization on $\mathrm{Mo}_{2} \mathrm{C}$-containing catalysts. Appl Catal A Gen 306:149-158

14. Yanhui W, Diyong W (2001) The experimental research for production of hydrogen from $n$-octane through partially oxidizing and steam reforming method. Int J Hydrogen Energy 26:795-800

15. Zhang J, Wang Y, Ma R, Wu D (2003) Characterization of alumina-supported $\mathrm{Ni}$ and $\mathrm{Ni}-\mathrm{Pd}$ catalysts for partial oxidation and steam reforming of hydrocarbons. Appl Catal A Gen 243:251-259

16. Subramanian R, Panuccio GJ, Krummenacher JJ, Lee IC, Schmidt LD (2004) Catalytic partial oxidation of higher hydrocarbons: reactivities and selectivities of mixtures. Chem Eng Sci 59:5501-5507

17. Qi A, Wang S, Fu G, Wu D (2005) Autothermal reforming of $n$ octane on Ru-based catalysts. Appl Catal A Gen 293:71-82

18. Williams KA, Schmidt LD (2006) Catalytic autoignition of higher alkane partial oxidation on Rh-coated foams. Appl Catal A Gen 299:30-45

19. Panuccio GJ, Schmidt LD (2006) Increasing olefins by $\mathrm{H}_{2}$ and $\mathrm{CH}_{4}$ addition to the catalytic partial oxidation of $n$-octane. Appl Catal A Gen 313:63-73

20. Panuccio GJ, Schmidt LD (2007) Species and temperature profiles in a differential sphere bed reactor for the catalytic partial oxidation of $n$-octane. Appl Catal A Gen 332:171-182
21. Mamedov EA, Cortes Corberan V (1995) Oxidative dehydrogenation of lower alkanes on vanadium oxide-based catalysts. The present state of the art and outlooks. Appl Catal A Gen 127:1-40

22. Burch R, Swarnakar R (1991) Oxidative dehydrogenation of ethane on vanadium-molybdenum oxide and vanadium-niobiummolybdenum oxide catalysts. Appl Catal 70:129-148

23. Andersen PJ, Kung HH (1993) The effect of oxygen binding energy on the selective oxidation of butane over $\mathrm{V} / \gamma-\mathrm{Al}_{2} \mathrm{O}_{3}$. Stud Surf Sci Catal 75:205-217

24. Kung HH, Michalakos PM (1993) Catalytic selective oxidation, ACS symposium series. Hattingh L, Washington DC, pp 389-408

25. Chaar MA, Patel D, Kung MC, Kung HH (1987) Selective oxidative dehydrogenation of butane over $\mathrm{V}-\mathrm{Mg}-\mathrm{O}$ catalysts. J Catal 105:483-498

26. Chaar M, Patel D, Kung HH (1988) Selective oxidative dehydrogenation of propane over $\mathrm{V}-\mathrm{Mg}-\mathrm{O}$ catalysts. J Catal 109:463-467

27. Blasco T, Lopez Nieto JM, Dejoz A, Vazquez MI (1995) Influence of the acid-base character of supported vanadium catalysts on their catalytic properties for the oxidative dehydrogenation of n-butane. J Catal 157:271-282

28. Kung HH, Kung MC (1997) Oxidative dehydrogenation of alkanes over vanadium-magnesium-oxides. Appl Catal A Gen 157:105-116

29. Blasco T, Lopez Nieto JM (1997) Oxidative dehydrogenation of short chain alkanes on supported vanadium oxide catalysts. Appl Catal A Gen 157:117-142

30. Dejoz A, Lopez Nieto JM, Marquez F, Vazquez MI (1999) The role of molybdenum in Mo-doped $\mathrm{V}-\mathrm{Mg}-\mathrm{O}$ catalysts during the oxidative dehydrogenation of $n$-butane. Appl Catal A Gen 180:83-94

31. Elkhalifa EA, Friedrich HB (2010) Oxidative dehydrogenation of $n$-octane using vanadium-magnesium oxide catalysts with different vanadium loadings. Appl Catal A Gen 373:122-131

32. Elkhalifa EA, Friedrich HB (2011) On the effect of hydrocarbon/ oxygen ratios during the dehydrogenation of $n$-octane over a $\mathrm{VMgO}$ catalyst. Catal Lett 141:554-564

33. Elkhalifa EA, Friedrich HB (2014) Oxidative dehydrogenation and aromatization of $n$-octane over $\mathrm{VMgO}$ catalysts obtained by using different $\mathrm{MgO}$ precursors and different precursor treatments. J Mol Catal A: Chem 392:22-30

34. Thomas JM, Thomas WJ (1997) Principles and practice of heterogeneous catalysis. VCH, Weinheim

35. Bowker M (1998) The basis and applications of heterogeneous catalysis. Oxford University Press, Oxford, UK

36. Patel D, Andersen PJ, Kung HH (1990) Oxidative dehydrogenation of butane over orthovanadates. J Catal 125:132-142

37. Valenzuela RX, Mamedov EA, Cortes Corberan V (1995) Effect of different additives on the performance of $\mathrm{V}-\mathrm{Mg}-\mathrm{O}$ catalysts in the oxidative dehydrogenation of propane. React Kinet Catal Lett 55:213-220

38. Stern DL, Michaels JN, DeCaul L, Grasselli RK (1997) Oxydehydrogenation of $n$-butane over promoted $\mathrm{Mg}$ - $\mathrm{V}$-oxide based catalysts. Appl Catal A Gen 153:21-30

39. Sugiyama S, Hashimoto T, Morishita Y, Shigemoto N, Hayashi H (2004) Effects of calcium cations incorporated into magnesium vanadates on the redox behaviours and the catalytic activities for the oxidative dehydrogenation of propane. Appl Catal A Gen 270:253-260

40. Sugiyama S, Hashimoto T, Tanabe Y, Shigemoto N, Hayashi H (2005) Effects of the enhancement of the abstraction of lattice oxygen from magnesium vanadates incorporated with copper(II) cations on the oxidative dehydrogenation of propane. J Mol Catal A: Chem 227:255-261 
41. Klisinska A, Loridant S, Grzybowska B, Stoch J, Gressel I (2006) Effect of additives on properties of $\mathrm{V}_{2} \mathrm{O}_{5} / \mathrm{SiO}_{2}$ and $\mathrm{V}_{2} \mathrm{O}_{5} / \mathrm{MgO}$ catalysts II. Structure and physicochemical properties of the catalysts and their correlations with oxidative dehydrogenation of propane and ethane. Appl Catal A Gen 309:17-27

42. Jin M, Lu P, Yu GX, Cheng ZM, Chen LF, Wang JA (2013) Effect of additives doping on catalytic properties of $\mathrm{Mg}_{3}\left(\mathrm{VO}_{4}\right)_{2}$ catalysts in oxidative dehydrogenation of cyclohexane. Catal Today 212:142-148

43. Elkhalifa EA, Friedrich HB (2015) Effects of boron and barium dopants on $\mathrm{VMgO}$ catalysts employed in the oxidative dehydrogenation of $n$-octane. Kinet Catal 56:212-221

44. Elkhalifa EA, Friedrich HB (2014) Magnesium oxide as a catalyst for the dehydrogenation of $n$-octane. Arab J Chem. doi: 10 . 1016/j.arabjc.2014.10.002

45. Dasireddy VDBC, Singh S, Friedrich HB (2013) Activation of $n$ octane using vanadium oxide supported on alkaline earth hydroxyapatites. Appl Catal A Gen 456:105-117

46. Corma A, Lopez Nieto JM, Paredes N (1993) Preparation of $\mathrm{V}-\mathrm{Mg}-\mathrm{O}$ catalysts: nature of active species precursors. Appl Catal A Gen 104:161-174

47. Corma A, Lopez Nieto JM, Paredes N (1993) Influence of the preparation methods of $\mathrm{V}-\mathrm{Mg}-\mathrm{O}$ catalysts on their catalytic properties for the oxidative dehydrogenation of propane. J Catal $144: 425-438$

48. Burch R, Crabb EM (1993) Homogeneous and heterogeneous contributions to the oxidative dehydrogenation of propane on oxide catalysts. Appl Catal A Gen 100:111-130

49. Oganowski W, Hanuza J, Kepinski L, Mista W, Maczka M, Wyrostek A, Bukowski Z (1998) New intermediate phases in formation at V-Mg-O catalyst. J Mol Catal A: Chem 136:91-104

50. Hayakawa S, Yoko T, Sakka S (1993) ${ }^{51} \mathrm{~V}$ NMR studies of crystalline divalent metal vanadates and divanadates. Bull Chem Soc Jpn 66:3393-3400

51. Blasco T, Lopez Nieto JM (1996) Nuclear magnetic resonance studies on supported vanadium oxide catalysts. Colloids Surf A Physicochem Eng Asp 115:187-193

52. Holgado MJ, San Roman S, Malet P, Rives V (2005) Effect of the preparation method on the physicochemical properties of mixed magnesium-vanadium oxides. Mat Chem Physic 89:49-55

53. Michalakos PM, Kung MC, Jahan I, Kung HH (1993) Selectivity patterns in alkane oxidation over $\mathrm{Mg}_{3}\left(\mathrm{VO}_{4}\right)_{2}-\mathrm{MgO}, \mathrm{Mg}_{2} \mathrm{~V}_{2} \mathrm{O}_{7}$, and $(\mathrm{VO})_{2} \mathrm{P}_{2} \mathrm{O}_{7}$. J Catal 140:226-242 